\title{
翻转课堂在少数民族预科教育中的研究 “以计算机基础课程"为例
}

\section{A Study of Flipped Classroom in the Preparatory Education of Minority Nationalities}

_- Computer-Based Basic Curriculum "Example

\author{
王晨晨 \\ Chenchen Wang \\ 新疆师范大学 中国・新疆 乌鲁木齐 830013 \\ Xinjiang Normal University, Urumqi, Xinjiang,830013,China
}

摘 要: 在信息技术蓬勃发展的今天,计算机基础课程为预科生进入本科阶段学习打下良好的基础。针对少数民族预科生的 《计算机基础》课程现阶段存在的问题,同时结合学生的特点,将翻转课堂教学模式融入实际的教学情景中。希望在少数民族 预科教育的实践中得到更广泛的推广。

\begin{abstract}
With the vigorous development of information technology, computer basic courses lay a good foundation for preparatory students to enter the undergraduate stage. In view of the problems existing in the present stage of the "computer foundation" course of the minority preparatory students, combined with the characteristics of the students, the flipping classroom teaching mode is integrated into the actual teaching situation. Hope to be more widely popularized in the practice of minority preparatory education.
\end{abstract}

关键词: 翻转课堂;少数民族预科生;计算机基础课程

Keywords : fipped classroom;minority preparatory students;basic computer courses

基金项目: 新疆师范大学青年优秀教师校级课题 “翻转课堂模式在预科生《计算机基础》教学中的应用研究”(项目编号: 3010020005 )的阶段性研究成果

DOI: $10.36012 /$ sde.v2i5.2094

\section{1 引言}

少数民族预科教育是介于高中教育和本专科教育之间 的一个过渡阶段,是一种较为特殊的教育层次。计算机基础 课程是面向所有预科学生开设的一门重要基础课程,学生修 完本门课程后, 不仅可以掌握计算机的基础知识, 更为重要 的是在实际应用能力方面得到训练, 实际动手能力得到提 高。为预科生进入本科阶段学习打下良好的计算机基础。

现阶段存在的主要问题: 大多数少数民族预科生在入校 前的计算机基础知识较为薄弱, 同时具备中国国家通用语言 的水平不一。

以教师为中心的一言堂教学模式, 导致学生处于被动接 受的状态, 学生的创造能力和教学效果难以提升。随着教育 信息化的推进,翻转课堂是顺应信息化时代的一种新型教学 模式。针对少数民族预科生的计算机基础课程,如何借助微 课视频开展翻转课堂的教学模式实践, 以期达到学生主动建
构认知的最大化、教学效果的最优化,即为论文的研究重点。

\section{2 翻转课堂世界研究现状}

翻转课堂的教学理念于 2007 年最早在美国“林地公园” 高中被提出来。主要解决缺课学生补课的问题。这种新型的 教学方法得以被传播和推广是在 2011 年 TED 演讲大会上, 萨尔曼・可汗讲解了 “可汗学院”创办的理念, 并首次提出了 翻转课堂的教学模型。可汗学院指导学生进行课下学习、完 成测试, 课上则设计课堂活动, 取得了一定的学习效果。支撑 翻转课堂教学的理论基础有许多,比较有影响力的是布鲁纳 的认知发现学习理论、互动理论、人本主义理论、建构主义理 论。翻转课堂的教学理念逐渐被世界各国学者关注并纷纷效 仿。有关翻转课堂的教学研究在中国也如雨后春笋般涌现出 来。美国富兰克林学院的教授 Robert Talbert 最早提出翻转 课堂教学模式(见图 1)。 


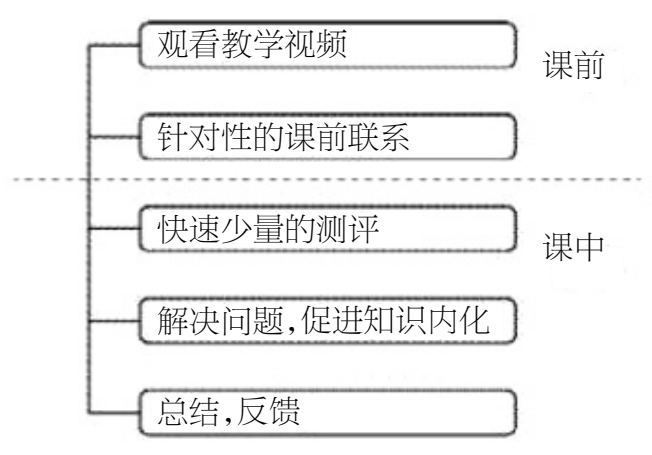

图 1 Robert Talbert 的翻转课堂结构图

关于翻转课堂的定义、内涵以及相关模式的讨论至今尚 无统一的描述。但其翻转大致可概括为教学理念、教学方式 的翻转。中国学者张渝江对翻转课堂的定义是: 翻转课堂是 指学生在课前自主学习时由教师分享的数字化学习资源 (如 音频、视频、电子教材等)。在正式的课堂教学过程中, 学生参 与教师设计的课堂活动 (如释疑、解惑、探究等) 的一种教学 形态。翻转课堂主要以学生为中心, 颠覆了传统的以教师为 中心的教学模式。教师的大部分工作被转移到了课前, 主要 围绕教学内容开展教学资源、教学方案和教学活动的设计与 开发, 知识传递过程放在了课外, 要求学生在课前就完成新 知识的学习。在此模式下, 对于教师和学生来说都是一个新 的挑战。

\section{3 借助微课视频开展翻转课堂教学模式研究}

翻转课堂教学模式中, 学生主要通过课前观看教师提供 的微课等资源来获取基本知识。“微课”是相对于“课”而言 的, 不同在于其“微”的特点。微课的视频一般都在 10 分钟之 内, 有明确且相对集中的知识点或技能要点, 学生可以根据 自身的需要进行定位, 学习进度也可以自行调整, 从而满足 不同学习者的需要进行有针对性的学习。微课作为碎片化学 习时代发展下的新课程形态, 能从多方面满足学习者的需 求。课前微课的学习可以随时随地进行, 不受时间和空间的 限制。学习节奏和学习频率也由学生自行决定, 学生渐渐地 从被动接受学习的传统模式转变为主动自主的学习模式。由 于基本的知识点作为微课, 已在课前由学生自主完成, 那么 课中的时间主要留给教师和学生进行答疑解惑、延伸拓展、 开展实践等互动, 弥补了传统教学模式中教师一言堂及师生 互动不足等问题。

\section{1 课前}

微课视频作为知识传授的主要载体, 是教学内容的具体 体现, 课前关键的环节就是教学微视频的制作。在微课视频 制作之前, 教师首先要深入研究少数民族预科生所使用的 《计算机基础》教材, 结合教学大纲, 明确学生最终应达到的 学习目标, 同时集中整合各章节的知识点和技术要点, 划分 若干知识单元。其次,新疆师范大学预科教育学院的预科生 大部分是不带专业入学, 根据中国国家通用语言的考试将之 分为民考汉一年制和民考民两年制进行分部教学。学生人学 前的计算机应用能力差异较大。视频的制作也应充分考虑不 同学习者的已有认知和个体差异。综上所述, 微课视频的制 作主要集中在实践性、操作性较强的第三章、第四章及第五 章的操作性知识, 大部分以实验的操作流程呈现。实验素材 的选取也主要以学生喜闻乐见的内容为主, 研究和分析教材 的三至五章的知识点后, 采用任务驱动法利用 Camtasia Studio 8 共录制微视频 42 份。这些视频已上传至蓝墨云班 课平台中, 学生可以随时随地地观看视频, 教师也可以借助 该平台了解学生的学习进度等学习情况。教材的一、二、六章 为计算机基础知识、计算机系统及计算机网络等理论性较强 的内容。此部分内容主要采取学生根据教师提前编制好的导 学案, 分组制作视频。在视频的制作过程中可以培养学生的 团队协作意识和主动探究等创新能力。

\section{2 课中}

翻转课堂教学模式中教师在课堂上主要发挥咨询和协 调的作用。课堂是学生自我展示的舞台, 少数民族预科生所 使用的《计算机基础》教材的第三至五章实践技能模块的内 容, 学生主要通过课前教师提供的微课视频等学习资源获取 新知识, 在课前学习过程中记录有困难, 或者有疑问的地方, 课堂上进行交流解惑答疑。教师结合学生的疑难问题及教学 内容的重难点设计有针对性的课堂活动, 通过快速少量的现 场实验测评, 了解学生的学习情况, 解决相关问题, 促进知识 的内化。第一、二、六章的学习以小组同学分角色完成各自的 任务, 课前借助网络、课件等学习资源形成初级视频作品, 课 堂主要以小组为单位选派代表展示和陈述视频作品, 其他小 组相互评价, 教师进行总结。小组之间相互取长补短, 不断修 改完善自己的作品。学生在解决实际技能实践问题过程中掌 握了相应的计算机操作, 在小组合作录制视频过程中, 不仅 培养学生解决问题的团队合作能力, 而且进一步提高了学生 的信息素养。

(下转第 25 页) 
在实际工作中, 辅导员自身的执行力包括执行上级决策、工作 任务的完成能力, 也包括了辅导员能以及按照规章制度作出 奖罚分明的工作判断。做到言必信、行必果, 高效的执行并按 照相关制度完成工作。也只有这样才能真正获得学生的信任 和尊敬,才能提升非职位权力的影响力。

\section{6 凝聚人心的感召力}

作为学生工作者, 辅导员希望自己能在学生之间有很强 的感召力, 能让学生有强烈的集体荣誉感和团队凝聚力。但 这种感召力的建立需要长期的过程, 不仅在平时的工作中, 辅导员要能够深入学生群体, 整合学生团队, 进行集体荣誉 感的建立。同时还需要在年级中树立良好的班风学风, 并以 自身感染力来凝聚学生、激励学生, 成为学生的知心朋友、人 生导师和引路人, 提升自己在学生心目中的影响力, 提升工
作领导能力。

在领导力的六维模型中, 六种能力是相辅相成的。高校辅 导员领导力提升的路径选择需要将理论联系实际, 高校需要 紧跟时代发展要求进行管理制度创新, 辅导员自身需要不断 学习, 努力提升工作领导力, 才能正确引领学生的成才之路。

\section{参考文献}

[1] 刘银花, 姜法奎.领导科学 (第三版)[M].王力行, 译.大连: 东北财经 大学出版社,2011.2:213.

[2] 杨思卓.六维领导力[M].北京: 北京大学出版社,2008.1.

[3] 李胜男. 高校辅导员的领导力提升研究[J]. 马克思主义文化理论, 2019(8):25.

[4] 叶金鹏. 论高校辅导员领导力提升[J]. 闽南师范大学学报(哲学社 会科学版), 2018(2): 158 .

\section{（上接第 21 页）}

\section{4 注意事项}

\section{1 翻转课堂教学模式使教师的角色发生转变}

翻转课堂教学模式要求教师具有极大的创造性和应变 能力。教师角色从传统的知识传授者, 转变成了学习的促进 者和指导者, 更重要的是成了整个学习过程的主线。这就需 要教师增加知识的深度和广度, 转变教学理念, 预先学会微 课视频的设计和制作方法。

\section{2 激发学生在翻转课堂教学模式中的自主学习的 兴趣}

对于翻转课堂而言, 学生“忙起来了”, 由于学生长期处 于教师教、学生学的模式, 学生课前需要自主学习微课视频 或者完成教师布置的分组任务, 教师则需要提高微课视频的 质量引发学生兴趣, 并且对学生课前的学习任务等做好设计 和安排, 同时给予督促监督。

\section{3 设计适合少数民族预科生的微课视频}

由于制作的微课视频需要同时在少数民族预科一年制 和两年制学生中使用。在制作微课视频时除了呈现基本的知 识点外还应涉及拓展延伸部分, 避免出现有的学生吃不饱,
有些学生吃不了的现象。

微课视频在制作时, 知识点要聚焦, 可用字幕、标记等方 式呈现关键内容; 画面简洁、语言精练; 避免出现与教学无关 的图标、背景等干扰信息。

\section{5 结语}

翻转课堂教学模式在快速发展的信息时代,对于学习理 念、学习资源、学习方式等发生了重大变革, 颠覆了教和学的 传统地位, 真正体现了以学生为中心的主导地位。针对少数 民族预科生的特点和《计算机基础》课程的性质, 借助 CS 制 作微课视频以及线上交互平台的使用, 不仅提高了少数民族 预科生的计算机应用能力、团队协作能力, 更重要的是提升 了学生的实践操作能力。

\section{参考文献}

[1] 何婧. 国内翻转课堂研究现状与反思[J].山东农业工程学院学 报,2020,37(6):106-109.

[2] 黎加厚,微课的含义与发展[J].中小学信息技术教育,2013(4): $10-12$.

[3] 张金磊,王颖,张宝辉. 翻转课堂教学模式研究[J].远程教育杂 志,2012,30(4):46-51. 